\title{
Flow Cytometry and Adipose Mesenchymal Stem Cells Characterization
}

\section{Vasiliki E Kalodimou}

Director at Flow Cytometry-Research and Regenerative Medicine Department, IASO-Maternity and Research Hospital, Greece

*Corresponding author: Vasiliki E Kalodimou, Director at Flow Cytometry-Research and Regenerative Medicine Department, IASO- Maternity and Research Hospital, Athens, Greece, Tel: Tel: 0030-210-6185203; Fax: 0030-210-6105711; E-mail: kalodimou@yahoo.gr

Received date: October 08, 2015; Accepted date: October 14, 2015; Published date: October 19, 2015

Copyright: ( 2015 Kalodimou VE. This is an open-access article distributed under the terms of the Creative Commons Attribution License, which permits unrestricted use, distribution, and reproduction in any medium, provided the original author and source are credited.

\section{Editorial}

In the field of regenerative medicine, basic research and preclinical studies have been conducted to overcome clinical shortcomings with the use of mesenchymal stem cells (MSCs). MSCs are present in adult tissues, including bone marrow and adipose tissue. For many years, bone marrow-derived stem cells (BSCs) were the primary source of stem cells for tissue engineering applications. However, recent studies have shown that subcutaneous adipose tissue provides a clear advantage over other stem cell sources due to the ease with which adipose tissue can be accessed as well as the ease of isolating stem cells from harvested tissue [1].

Adipose tissue is an abundant source of mesenchymal stem cells, which have shown promise in the field of regenerative medicine. Furthermore, these cells can be readily harvested in large numbers with low donor-site morbidity. During the past decade, numerous studies have provided preclinical data on the safety and efficacy of adipose-derived stem cells, supporting the use of these cells in future clinical applications [2].

There is no consensus when it comes to the nomenclature used to describe progenitor cells from adipose tissue-derived stroma, which can sometimes lead to confusion. The term PLA refers to adiposederived stromal cells and adipose-derived stem cells (ASCs) and describes cells obtained immediately after collagenase digestion. ASCs exhibit stable growth and proliferation kinetics and can differentiate toward osteogenic, chondrogenic, adipogenic, myogenic, or neurogenic lineages in vitro $[3,4]$.

Today, it is accepted that new fat cells are made throughout life. It has been shown that human adult adipocytes have a roughly $10 \%$ turnover rate (Spalding et al.). While genetic background may play a role in fat storage. It is clear that adipose is a crucial player in a complex network balancing energy homeostasis, and as such, expands to accommodate increased energy intake.

Fat growth is variable from depot to depot and has varying growth rates through a human lifespan. On a cellular basis, whether there is a relationship between hypertrophy and hyperproliferation mediated by a maximum cell size or other molecular trigger remains to be definitively resolved. Further, the complement of cells that give rise to adipose tissue and under what circumstances remains to be experimentally shown $[5,6]$.

\section{The following criteria were used to characterize ADSCs by flow cytometry:}

Positive markers: Cells must show $>95 \%$ positivity for expression of cell-surface antigens CD29, CD44, CD73, CD90, CD105, and CD166, CD 271.
Negative markers: Cells must show $<2 \%$ positivity for expression of cell-surface antigens CD14, CD31, CD 34, CD45, CD 133, and Lin1.

The cultured MSC's also express on their surface markers such as CD73, CD90 and CD105, while lacking the expression of CD11, CD14, CD19, CD34, CD45, CD79 and HLA-DR $[7,8]$.

As concluded remarks, the use of ADSC counting by flow cytometry constitutes a potential powerful tool in regenerative medicine and in gene therapy in vitro and in vivo. They have an extensive proliferative potential and are able to differentiate into various cell lineages such as adipocytes, osteoblasts, cardiomyocytes, vascular endothelial cells, pancreatic b-cells, and hepatocytes. Due to these important features their use in clinical trials has been increased. It has been documented that the cells engraft successfully in patients and cause beneficial effects. ADSC extraction is easily obtained in comparison to BMSC's cells. The procedure is safe and minimally invasive.

Last, there is no risk of immune rejection with autologous cells in comparison with embryonic stem cells or induced pluripotent stem cells (iPSC's). Therefore, ADSC's are a useful tool in the field of regenerative medicine. However, it will be a while before using those cells as a routinely applied therapy in clinics. Further preclinical and clinical studies are needed to determine whether ADSC's therapies can fulfill the expectations and if they can be used successfully to treat disorders for which current medical and surgical therapies are either impractical or ineffective.

\section{References:}

1. Hausman DB, DiGirolamo M, Bartness TJ, Hausman GJ, Martin RJ (2001) The biology of white adipocyte proliferation. Obes Rev 2: 239-254.

2. Caplan AI (1991) Mesenchymal stem cells. J Orthop Res 9: 641-650.

3. Pittenger MF, Mackay AM, Beck SC, Jaiswal RK, Douglas R, et al. (1999) Multilineage potential of adult human mesenchymal stem cells. Science 284: 143-147.

4. Caplan AI (2007) Adult mesenchymal stem cells for tissue engineering versus regenerative medicine. J Cell Physiol 213: 341-347.

5. Schäffler A, Schölmerich J, Salzberger B (2007) Adipose tissue as an immunological organ: Toll-like receptors, C1q/TNFs and CTRPs. Trends Immunol 28: 393-399.

6. Izadpanah R, Trygg C, Patel B, Kriedt C, Dufour J, et al. (2006) Biologic properties of mesenchymal stem cells derived from bone marrow and adipose tissue. J Cell Biochem 99: 1285-1297.

7. Kalodimou VE (2013) Basic Principles in Flow Cytometry. Md.: AABB Press, Bethesda.

8. Kalodimou VE (2015) A Handbook to Mesenchymal Stem Cells in Regenerative Medicine. Specg Co.

This article was originally published in a special issue, entitled: "Management of Peripheral Arterial Disease", Edited by Smriti. M. Krishna 